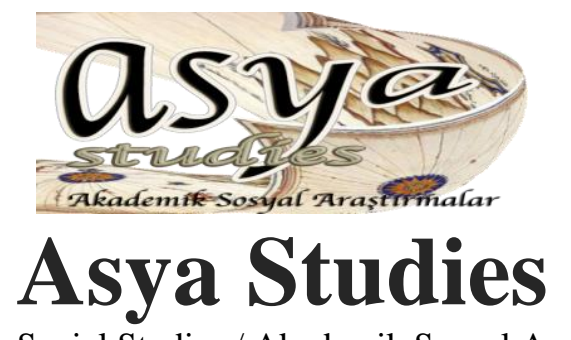

Academic Social Studies / Akademik Sosyal Araştırmalar Year: 5 - Number: 16, p. 305-308, Summer 2021

\title{
Machiavelli, Niccolò (2018). Prens. Ankara: Doğu Batı Yayınları
}

\section{Kitap İncelemesi / Book Review \\ Makale Geliş Tarihi / Article Arrival Date 18.03.2021}

Makale Kabul Tarihi / Article Accepted Date 24.04.2021

Makale Yayın Tarihi / Article Publication Date 30.06.2021

\section{Asya Studies}

\section{Barış Sür}

Doktora Öğrencisi / İstanbul Medeniyet Üniversitesi, Lisansüstü Eğitim Enstitüsü, Siyaset Bilimi ve Kamu Yönetimi Anabilim Dalı, barissur@hotmail.com

\section{ORCID ID}

https://orcid.org/0000-0002-9051-3285

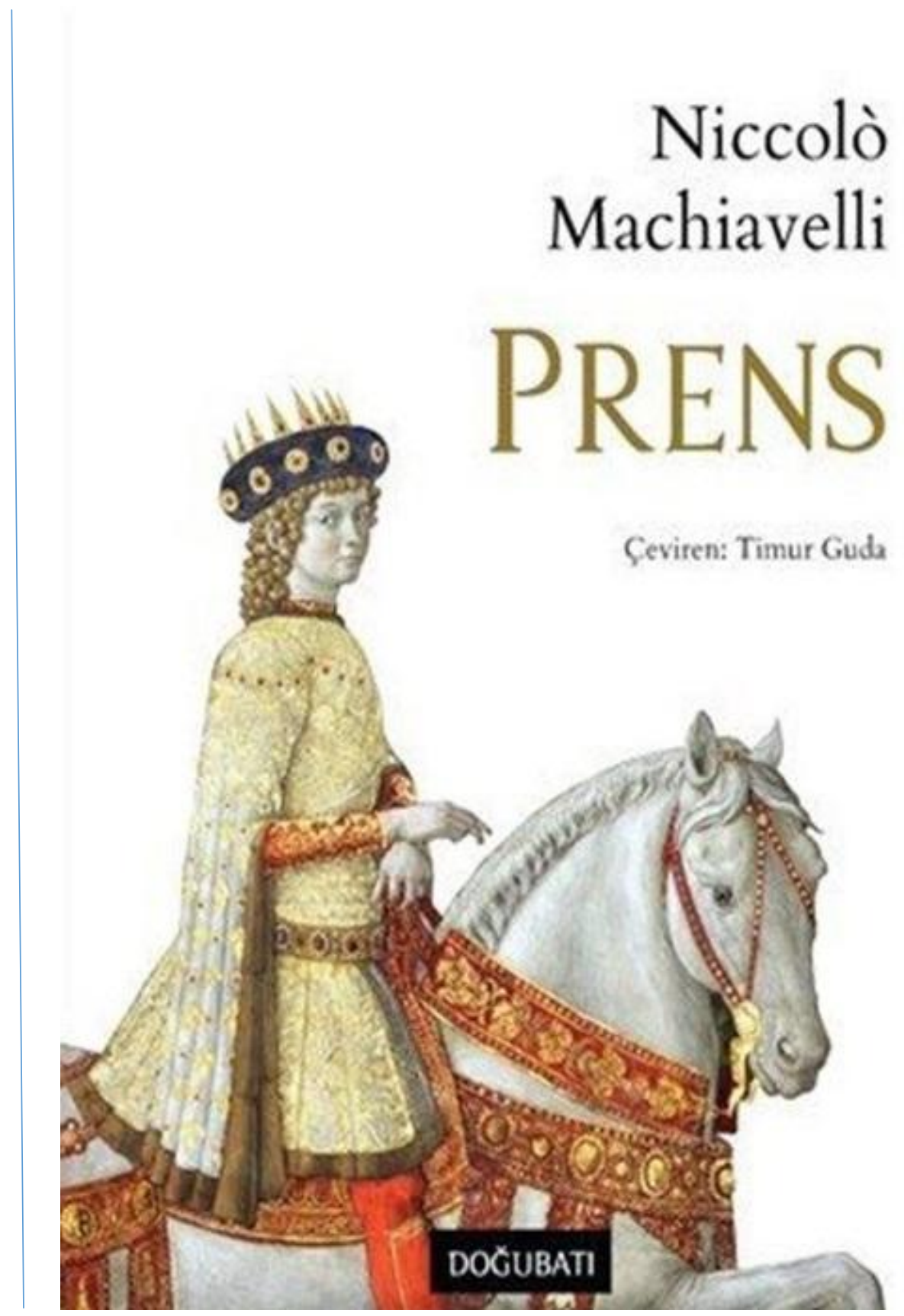

Citation Information/Kaynakça Bilgisi

Sür, B. (2021). Machiavelli, Niccolò (2018). Prens. Ankara: Doğu Batı Yayınları. Asya Studies-Academic Social Studies / Akademik Sosyal Araştırmalar, 5(16),305-308. 


\section{GİRIŞ}

Prens, iyi bir prensi mi yoksa ideal bir prensliği mi tasvir eder? Machiavelli’nin Prens’i, tahayyül edilen prens midir yoksa gerçekte olması gereken midir? Bu eserin Machiavelli'ye, modern siyasi düşüncenin kurucusu tacını giydiren özelliği nedir? Machiavelli, bazı aydınlar tarafından gerçekçi politikanın en etkili ismi olarak görülürken bazıları tarafından ise hükümdara kötülük ruhu aşılayan bir çılgın olarak değerlendirilmiştir. Ancak onun bu eseri, yazılmasından bu yana beş asır geçmiş olmasına rağmen siyasi düşüncedeki önemini korumuştur. Uzun uğraşlar sonucu oluşturulan kapsamlı çalışmaların aksine Prens, sade dil kullanılan, yeterince açı ve sonuç odaklı mütevazı bir risale hükmündedir. Doğu Batı Yayınları'ndan 2018'de çıkan kitabın orijinal dilinden çevirisi ise Timur Guda'ya ait. Kitabın içeriği kadar yazılmasına neden olan etmenler de önem arz etmektedir. Bu nedenle arka planının da okuyucuya aktarılması amacını taşıyan çalışmada Prens dört bölümde ele alınmıştır. İlk bölümde içinde bulunduğu koşullar gereği böyle bir kitabı yazmaya ihtiyaç duyan kişi olarak Machiavelli incelenmiş olup, ikinci bölümde kitabın oluşum süreci ve özellikleri yer almaktadır. Üçüncü bölümde kitap içeriğiyle birlikte öğüt, tavsiye ve atıflar bulunurken, son bölümde ise değerlendirmelere yer verilmiştir.

\section{Machiavelli Üzerine}

Machiavelli deha mıdır, çılgın mıdır? Neden despot bir prensi yeğlemiştir? Bu soruların cevaplarını alabilmek için Machiavelli’yi yaşadığı dönem koşulları çerçevesinde incelemek gerekmektedir. Machiavelli politikayı bir var olma savaşı olarak kabul eder. Bu nedenle merhamet ve nezaket beklenmeyen düşmanlara karşı alaycı ve acımasız bir politika tavsiyesinde bulunur. Yönetim ve ahlak kurallarının ayrımını yapan ilk Avrupalı düşünür olmakla birlikte egemenliğin korunması için devlet liderinin suç teşkil eden önlemleri dahi almasından yanadır. Mavhiavelli'nin bu şekilde düşünmesinde Roma'dan kalan cumhuriyetçi gelenek ile güncel siyasi düşünceleri sentezlemesinin etkisi büyüktür. Bu nedenle Söylevler adlı eserinde görüldüğü gibi onun cumhuriyetçi kişiliği Yeni İtalya'nın kesinlikle bir cumhuriyet olması gerektiğine inanmaktadır. Ancak Prens'te, buna ulaşman tek yolunun güncel siyaset gereği despotik yöntemler başvurmak olduğu kanısını taşımaktadır. Hatta bu yaklaşımı, etik ve erdemli hükümdarın aksine tahta tutunmak adına aldatma ve öldürme mecburiyetindeki bir hükümdarı tanımlamasıyla sonuçlanmış, aldığ1 yoğun eleştirilerle birlikte anti-makyavelizm akımının doğmasına da yol açmıştır. Özellikle Kilise karşıtı değerlendirmeleri bu akımın güçlenmesine sebebiyet vermiştir. Devlet adamı ve diplomat kimliği ile Cesare Borgia, Papa, Germen İmparatoru Maximilian gibi dönemin etkili isimleriyle çalışma ve savaşlara katılma firsatı elde etmiştir. Böylece farklı devlet ve hükümdarları inceleme fırsatı bulmuş, birçok savaş taktiğine tanıklık etmiştir. Bu tecrübelere istinaden hükümdara Floransa'nın istikrarı için paralı askerler yerine kendi ordularını kurmasını ve daha kararlı bir siyasi yönetim oluşturmasını söylemiştir. İstikrar için tek yolun ihtiyat ve düzenli ordu olduğunu aktarmıştır. Mediciler'in Floransa'ya dönmesi ile cumhuriyetin faaliyetlerine taviz vermesinden ötürü kamudan yasaklanmış ve göz hapsine alınmıştır. Burada kamudan yasaklı olmanın verdiği pişmanlık ve yeniden bir pozisyon elde edebilme isteği ile tecrübelerinden yola çıkarak, daha sonra Prens adını alacak olan bir risale hazırlamıştır.

\section{Prens Üzerine}

Machiavelli, yasaklı olduğu dönemde Floransa'da hükümranlığını sürdüren Medici hanedanlığına ithafen İtalya'nın siyasi parçalanması, yetersiz bulduğu paralı askerlerin durumu gibi olumsuzluklar üzerine tecrübe ve bilgi birikiminden yararlanarak Prens'i yazmıştır. Yazın açısından sade bir form kullanmış, dönemin halk dili (Floransa lehçesi) ile yazarak süslemelerden kaçınmıştır. Hayal gücünden uzak, gerçeğin analizini yaparak insanların hayatında olmayan ütopik bir devletten bahsetmemiştir. Orijinal başlık İtalyanca'da "Prenslikler Hakkında" anlamına gelen De Principatibus olmakla birlikte Machiavelli’nin vermediği bir ad olan Il Principate ile bilinmektedir. Prenslik ve prensin özelliklerini aktarmasına rağmen kitap Prens olarak isimlenmiştir.

Kitap bir ithaf mektubu ve ardından gelen 26 bölümden oluşuyor. Bu 26 bölümü konusuna göre sınıflandırmak mümkün. Floransalı düşünür I-XI. bölümlerde prensliklerin özelliklerinden bahsediyor. XII-XIV. bölümlerde ise paralı askerler hakkında bilgi veriyor. XV-XXIII bölümlerde prensin özellikleri yer alırken, XXIV-XXV bölümlerde prenslere düzenlenen komplolardan söz ediyor. Kitabın son bölümü ise Lorenzo Di Mecidi’ye İtalyan şehir devletlerinin başına geçerek yarımadayı kurtarmaya yönelik davet niteliğindedir. 


\section{İnceleme}

Machiavelli, hükümran olanın sadakat, cömertlik, merhamet gibi bir takım olumlu niteliklere sahip olmakla birlikte gerçekte ihtiyaca göre sadakatsiz, yalancı ve acımasız görünmek mecburiyetinde kalacağını söyler. Bunu şöyle açmak mümkün: Prens aslında iyi olmalıdır, fakat insanlığın kötülüğe meyilli olması nedeniyle kötü olmayı bilmek, kötü zamanlarda yönetim kabiliyetini kaybetmemek için kötü görünmek zorundadır. Aksi takdirde zayıf olarak görülecektir ve iyiliği daima suiistimal edilecektir. Bu noktada yazar, 14 yıllık hükümranlığı boyunca mahkeme sonucu olmadan tek kişiyi bile öldürtmeyen hakkaniyetli, mütevazı ve insancıl Alexander'ın, kadınsı yönetim sergilemekle küçümsenip ve kendi ordusu tarafından öldürülmesi örneğini paylaşıyor. Prens cömert olmamalıdır. Çünkü savurgan tavrı ile tüm servetini harcayıp, kaynak bulmak adına halka ağır bedeller ödetip vergileri arttırabilir. Acımasız olmalıdır çünkü yeni kazanılan yerlerde düzenin kurulması, itibar ve otoritenin sağlanması için sert tedbirler almalıdır. Kısacası Machiavelli’ye göre prens, tuzakları görebilen kurnaz bir tilki, korkusuzca avlanabilen yırtıcı bir aslan gibi olmalıdır. Ayrıca düzen tesis edildikten sonra halkla barışık olmayı prensin en önemli görevi olarak görür. Bunu sağlamak için halkının mal ve onuruna el uzatılmasını engellemesi yeterlidir. Bununla birlikte yazar ideal bir prense (Medici Prensi) davranış analizi yapar ve bunu çok açık bir dille ifade eder. İnsanları yönetme ve iktidarda kalma yolları üzerine önerilerde bulunur.

Prensliklerle ilgili kısımda yazar iki tür prenslikten bahsediyor: Veraset yoluyla devredenler ve yeni elde edilen (karma) prenslikler. Bunların elde edilmesi kadar elde tutulabilmesinin de ilkelerini detaylıca anlatıyor. Gerek tarih bilgisi gerekse gözlemlerinden hareketle iyi bir analiz yaparak yaşanmış olaylardan örnekler veriyor ve okuyucuyu farklı açılardan düşünmeye sevk ediyor. Bunun dışında prensliklerin elde ediliş şekline göre de bir ayrım yapıyor. Kendi orduları tarafından erdemle ele geçirme, başka ordular tarafından ele geçirme, darbe veya dış müdahale şeklinde detaylandırdığı hıyanet ile ele geçirme, sivil prenslik gibi çeşitlendirmelerde bulunarak her biri hakkında dikkat edilmesi gereken incelikleri aktarıyor. Sivil prenslik olarak adlandırdığı devlet türünde egemenliğin kaynağını halka ve desteğini aldığı nüfuzlu kimselere dayandırıyor. Temelleri iyi atılmayan bir devletin yükselişe değil kendi çöküşüne ilerleyeceğini söyleyerek temelleri yasalara ve orduya dayandırıyor. Ayrıca yeni prenslerin veraset yoluyla prens olanları örnek almasının da çöküşü getireceğinden söz ediyor. Yapı farklılığını dile getiren yazara göre verasetle elde edilen prensliklerde geleneklerin devam ettirilmesi büyük oranda yeterli olacaktır. Ancak yeni elde edilen prensliklerde reform değil, devrim niteliğinde değişimler gereklidir. Elde tutulması en zor prensliklerde uygulanacak en doğru taktiğin prensin ikametini taşıması olduğunu söyleyerek Sultan I.Murad'ın 1362 Sazlıdere Savaşı ile kazanılan Edirne'yi başkent ilan etmesini örnek gösteriyor. En zor elde edilecek prensliklerde yine Türkleri örnek gösteren yazar, prense koşulsuz biat edilen toplumlarda işgalin ancak ordu gücüne güvenilerek yapılabileceğinden bahsediyor.

Machiavelli, eserin yazılış amaçlarından birini oluşturan paralı asker sorunlarına dikkat çekerek prensin kendi halkından oluşturulan ve kendisinin komuta edeceği orduları benimsemesi gerektiğini söylüyor. Ayrıca prensin gerektiğinde akıl alabileceği bir kurulu da olmalıdır. Ancak bu kurul yalnız prens istediğinde görüş bildirmelidir. İttifaklara da değinen yazar iki kurala dikkat çekiyor. Birincisi, zaferden sonra mahkum olunacağı için asla daha güçlü devletlerle ittifak yapılmaması. İkinci kural ise ittifaklar daima şüphe barındıracağından asla koşulsuz güven duyulmamasıdır. Son olarak çalışmada egemenliğin cumhuriyet ya da prensliklerde toplandığını söyleyerek çalışma kapsamı dışında kalan cumhuriyetler için bir diğer eseri Titus Livius'un Illk On yılı Üzerine Söylevler'e referans veriyor.

\section{Eleştirel Bakış}

Machiavelli'nin prens tasviri aslında yalancı, kötü niyetli, cömert olmayan, acımasız olma gerekliliğinden çok, şartlar gereği iyi niyetli, cömert, merhametli ve dürüst olamama zorunluluğuyla alakalıdır. Kendisi tarafından dile getirilmemiş olsa da yazılarından "amaca giden her yol mubahtır" çıkarımında bulunmak mümkün. Bu yaklaşımı anti-makyavelizm akımına yol açmış olmakla birlikte etik kurallarına uygunluğu da tartışmalıdır. Ancak Machiavelli'nin realizm açısından değerlendirilmesi, söylemlerindeki haklılık payını arttıracaktır. İtalyan politikacının yaklaşımları üzerine kurulu Makyavelizm akımına karşıt niteliğinde somut bir çalışma 18. yüzyıl aydınlarından Voltaire tarafından kaleme alınmıştır. Voltaire, Prusya Kralı II. Friedrich’in özel isteğiyle Prens’ $i$ bölüm bölüm inceleyip reddettiği çalışma olan Anti-Machiavel (Voltaire, 2016) adlı eseri kaleme almıştır. Birçok hükümran tarafından kitabın dikkate alındığı düşünülecek olursa Machiavelli’nin diplomasinin arka planda kalmasına ve yayılmacı politikaların hak görülmesine yol açan bir isim olduğu düşünülebilir. Öyle ki 
onun bu görüşlerinin 19. yüzyılda totaliter rejimlerin sıkça başvurduğu bir yönetim stratejisi olduğu açıkça görülmektedir. Ancak egemen açısından bakıldığında, iktidarın korunması adına ya da yeni egemenlik alanı kazanmak adına çok önemli nasihatler içeren bir el kitabı niteliğinde olması da göz ardı edilmemelidir. İktidar için tek yolun ihtiyat ve ordu olduğunu söylemesi Max Weber'in devleti meşru şiddet aracı olarak tanımlamasına dayanak oluşturduğu düşünülebilir. Ayrıca yalnız gerçek bir devletin varlığından söz etmesi, çağdaşı Thomas More'un Ütopya'sına bir gönderme olarak kabul edilebilir.

Sonuç olarak bu kitap, sınır değişimin en alt seviyeye indiği ve sınır geçirgenliğinin gün geçtikçe arttığı günümüz koşullarında fetih odaklı temel bilgiler veren faydalı bir kitap olarak düşünülmemeli. Prens, yeni toprak elde etme ve devlet kurma ihtiyaçları, koşulları, sonuçları ile buradaki egemenliği korumada karşılaşılacak sorunları, atılacak adımları o anın şartlarına göre düşünüp yorumlayabilmeyi sağlayan bir kılavuz niteliğindedir. Yazar resmin kendisinden ziyade arka planını görmeyi, olayları bir bütün olarak değerlendirmeyi öğretiyor. Tıpkı bu kitabı nasıl okumamız gerektiğini işaret ettiği gibi. Bu doğrultuda siyaset bilimi ve özellikle siyaset psikolojisi, tarih ve kamu yönetimi ile ilgili akademisyenler, araştırmacılar ve öğrencilerin arka planıyla birlikte bu kitabı okuması yerinde ve faydalı olacaktır.

\section{KAYNAKÇA}

Machiavelli, N. (2018). Prens. Ankara: Doğu Batı Yayınları.

Voltaire, F. (2016). Büyük Frederik-Anti Makyavel. İstanbul: Yeditepe Yayınevi. 